


\section{Edmund Husserl en el ordoliberalismo alemán. Extrañezas, resonancias y actitudes}

Pablo Martín Méndez

Universidad Nacional de Lanús, Argentina

Resumen

En el curso titulado Nacimiento de la Biopolitica —o, más específicamente, en la serie de fragmentos que se reparten a través de dicho curso-, Michel Foucault señala la existencia de una casi desapercibida relación entre la filosofía de Edmund Husserl y el discurso crítico del denominado ordoliberalismo alemán. Partiendo desde los aportes de Foucault, el presente artículo pretenderá precisar los términos y los alcances de esa relación. El objetivo tiene una importancia muy particular: más allá de Husserl y el ordoliberalismo, o más allá de la crítica contra la actitud natural y la consecuente necesidad de adoptar el método de aprehensión de esencias, emergerían las más extrańas posibilidades de pensamiento. De ahí también se sigue la pregunta que este artículo no podrá evitar ni contestar del todo: ¿hasta qué punto tales posibilidades resuenan en nuestra actualidad e incluso en nosotros mismos?

Palabras clave: Actitud natural, liberalismo económico, economía de competencia, esencia, alternativa ordoliberal. 


\section{Abstract}

In the course titled Birth of the Biopolitics —or, more specifically, in the series of fragments that are distributed through the course-, Michel Foucault notes the existence of an almost unnoticed relationship between the philosophy of Edmund Husserl and the critical speech of the denominate german ordoliberalism. Starting from the contributions of Foucault, this article will pretend to specify the terms and the effect of this relationship. The objective has a very special significance: beyond Husserl and ordoliberalism, or beyond criticism against the natural attitude and the consequent need to adopt the method of apprehension of essences, will emerge the strangest possibilities of thought. Hence also continues to be the question that this article may not avoid, nor answer of all: to what extent such possibilities resonate in our present and in ourselves?

Keywords: Natural attitude, Economic liberalism, Economy of competition, Essence, Ordoliberal alternative.

\section{Introducción}

$\mathrm{V}$ amos a comenzar poniendo ciertas nociones entre paréntesis. Vamos a hacerlo así para que nuestra propia indagación no se ponga en el siguiente aprieto: o bien recorrer los caminos ya varias veces recorridos, o bien aspirar hacia una originalidad tal que de antemano torne espurio todo lo que aquí pudiera pensarse y decirse. La indagación venidera renuncia ante las descomunales pretensiones de originalidad y, al mismo tiempo, evita las aparentemente ineludibles necesidades de repetición: en primer lugar, porque recoge pequeńísimos segmentos de la obra de $\mathrm{Mi}$ chel Foucault y desde allí transita la intrincada relación que une a dos discursos sumamente específicos; en segundo lugar, porque al momento de abordar la relación en cuestión procura que las recurrentes y enquistadas nociones de autor, de influencia y de 
tradición permanezcan ubicadas entre paréntesis. Estas nociones tienen que ponerse efectivamente entre paréntesis, pues justifican la creencia de que el pensamiento se constituye con nombre y apellido y que sólo se trasmite o comunica a través de relaciones precisas y unívocas (Foucault, 2008a: 33- 34); más aún, estas nociones deberían disolverse y dispersarse, dado que impiden ejecutar otro modo de repetición y desarrollar otra clase de originalidad. Teniendo semejante estrategia en mano, intentaremos indagar ahora la relación que señalara Foucault en su momento y que ha pasado casi desapercibida, nos referimos a la relación que mantienen la filosofía de Edmund Husserl y el discurso crítico del denominado ordoliberalismo alemán (Foucault, 2008b: 152-154). ${ }^{1}$

Poco importa que el ordoliberalismo realice alguna mención del consabido nombre, así como poco nos interesarán las influencias directas o indirectas que Husserl ejerza eventualmente en aquel discurso; pero si el interés no pasa por allí, si ni siquiera nos importa realizar una suerte de estudio erudito sobre la relación entre Husserl y el ordoliberalismo alemán, ¿cuál es entonces la necesidad que guía al presente trabajo? Hay que abandonar los detalles más vistosos y escuchar más bien las cuestiones que resuenan en medio de Husserl y el ordoliberalismo; hay que escuchar los resquebraja-

${ }^{1}$ El ordoliberalismo, o la corriente económica y política conocida también como Escuela de Friburgo y más tarde como Neoliberalismo alemán, nace durante la década de 1930 bajo el impulso de Walter Eucken y expresa gran parte de su ideario en la revista Ordo, publicada durante la década siguiente. Es necesario recordar que los programas de reforma propuestos por dicha corriente - $y$ que se denominarían luego como Economía social de mercado- contribuyeron enormemente a definir la orientación de la política económica implementada en la Alemania de posguerra (Castro-Gómez, 2010: 178 y ss.). Para un abordaje histórico sobre ordoliberalismo alemán y para una definición del mismo como doctrina económica, política e incluso filosófica, véase el valioso texto de François Bilger, titulado La pensée économique libérale dans l'Allemagne contemporaine (1964). Hasta donde se sabe, Foucault extrajo la mayor parte de sus observaciones de este texto. 
mientos de todas las divisiones previamente establecidas y atender a la apertura de las más extrañas posibilidades de pensamiento. ¿Qué nos dirían esas posibilidades?, ¿qué interés concreto podrían reportar para nosotros, quienes nos situamos en estas coordenadas espaciales y temporales? Hay que seguir escuchando cuanto resulte necesario escuchar: así advertiríamos que de entre Husserl y el ordoliberalismo emerge un modo de pensamiento que interpela y compromete a nuestra propia actualidad. Así, también, la atenta lectura nos permitirá llegar hasta el punto donde los nombres se pierden y confunden entre sí, el punto donde ya no captamos bien quién es el que está hablando exactamente: ¿Husserl, el ordoliberalismo o, quizá, nosotros mismos? ${ }^{2}$

\section{Más allá de la ingenuidad naturalista}

Husserl solicitaba una nueva y radical actitud, lo hacía de seguro siguiendo el atrevido afán de comenzar todo de nuevo, pero además por la necesidad de que el empirismo —o la actitud que postula a la experiencia el único acto posible mediante el cual se dan las cosas mismas - quedase en el justo lugar que le correspondía. Tiempo más tarde, con similar osadía, los diferentes lineamientos del discurso ordoliberal convergen en un criterio específico y sin duda disruptivo, a saber: que el mercado no puede concebirse

${ }^{2}$ Puede que a partir de aquí ya no haga falta ninguna aclaración ulterior sobre el objetivo de este artículo; sin embargo, para evitar cualquier equívoco, agregaremos que tal objetivo no se agota en una mera descripción del ordoliberalismo y, menos aún, en la defensa o la reivindicación de sus ideas económicas y políticas. Antes bien, el interés que nos guía consiste en advertir hasta qué punto las ideas ordoliberales son nuestras propias ideas, o hasta qué punto el ordoliberalismo y las posteriores vertientes neoliberales han afectado nuestro actual modo de constituirnos como sujetos. Si ello fuese cierto, o por lo menos presentido, se podría sugerir finalmente que toda crítica contra el ideario neoliberal debe dirigirse en cierto momento hacia aquel modo de constitución. 
como un fenómeno natural y espontáneo, y que su propia existencia requiere más bien de cierto esfuerzo y de cierta reflexión previa. Dos cambios sucesivos de actitud, cuya cercanía espacial y cronológica confirmaría la mera relación de causalidad o el variado tráfico de influencias que siempre se produce entre las diferentes tendencias y corrientes de pensamiento. Nosotros no esclareceremos ni discutiremos esa confirmación, pues nos parece que la cuestión crucial reside en otra parte. Se trata de buscar una relación distinta, de abandonar momentáneamente la simple noción de influencia para iniciar en cambio el titubeante recorrido a través de ciertas conexiones menos visibles y más diseminadas. Se trata también de establecer un campo de comunicación que resultará demasiado estrecho frente a la historia de las ideas aunque sumamente extenso ante el juego de las influencias directas y concretas. Añádase de inmediato que aquí tampoco ha de faltar prudencia. Al menos en principio, deberemos precisar cuidadosamente los lugares críticos y las controversias de inmediato desatadas; en efecto, sólo éstascontribuyen a que el discurso se dispare hacia horizontes muchas veces impredecibles e insospechados y nos permiten ingresar ahí donde los nombres tienden a perderse y las obras a tornarse más difusas.

Hechas estas salvedades, recorramos entonces el lugar crítico siempre frecuentado y conocido, el lugar desde el cual Husserl levanta sus objeciones contra las desmesuras de la denominada actitud natural. Se sabe muy bien que la crítica husserliana obedece al intento de construir los cimientos propicios para la edificación de la fenomenología y se entiende perfectamente que los continuos y numerosos reparos apuntan a fundamentar la esfera del conocimiento no experimentable. ¿Pero acaso el alcance de esas críticas queda detenido exactamente aquí?, ‘acaso no emergerá algo más de las rupturas y de las grietas provocadas por las mismas críticas? Husserl sostiene que la actitud natural se vuelca hacia los objetos 
del mundo, los objetos que afloran en cada momento como simplemente dados: " $\mathrm{La}$ 'realidad' la encuentro [...] como estando ahí delante y la tomo como se me da, también como estando ahî". Cualquiera advertiría enseguida que semejante actitud resulta de por sí bastante simple, tan simple que ni siquiera incluye la posibilidad de un mínimo cuestionamiento sobre el darse de todo objeto: "Ningún dudar de datos del mundo, ni ningún rechazarlos, altera la tesis general de la actitud natural" (Husserl, 1985: 69). Aunque sería más difícil notar que la actitud natural propiamente dicha no sólo tiende a volverse hostil y avasallante, sino también escéptica y en última instancia absurda. Ocurre que las ciencias del mundo, o las ciencias de la actitud natural, avanzan con tal firmeza que a la larga, de manera paradójica, despiertan no pocas ambigüedades: "El conocimiento natural, que progresa, en las distintas ciencias, siempre acompañado del buen éxito, está completamente seguro de que alcanza certeramente su objeto, y no tiene ningún motivo para encontrar aporía en la posibilidad del conocimiento ni en el sentido del objeto conocido" (Husserl, 1982: 42). Que las ciencias naturales avancen con total seguridad y firmeza, que la obtención del conocimiento preciso y efectivo sea en definitiva la única preocupación capaz de movilizarlas, de más está decirlo, no puede tener nada de malo; más aún, Husserl recordará recuerda, una y otra vez, que aquella seguridad y aquella preocupación extremadamente limitada permiten y garantizan el avance de las ciencias naturales. En todo caso, el problema acuciante aparece cuando los logros obtenidos fomentan la propagación de una corriente de pensamiento cuya falta de límites la llevaría a elevarse pronto como la convicción predominante y decisiva. Husserl habla de empirismo filosófico, de naturalismo empirista o bien de empirismo a secas. Sea como fuere, la cuestión crucial residiría en el hecho de que esta corriente de pensamiento establece una equiparación inmediata entre los juicios racionales o científicamente fundados y la nece- 
sidad de dirigirse hacia la realidad natural y experimentable: "Así, ciencia auténtica y ciencia empírica son para el empirista la misma cosa”. Así también, como seguirá sosteniendo Husserl, el error fatal del empirismo se remonta a la exorbitante pretensión que lo conduce a aunar la exigencia de dirigirse hacia la realidad estricta con la exigencia de que todo conocimiento posible encuentre sus fundamentos en la experiencia: "Afirmar rotundamente que todos los juicios admiten fundamentación empírica (...) es una 'construcción especulativa a priori, que no resulta mejor porque esta vez venga del lado empirista" (Husserl, 1985: 48- 49). Ya más directa o indirectamente, ya de modo concentrado o disperso, las objeciones y las críticas de Husserl comienzan a resonar en los discursos ordoliberales - ya pronto esos discursos nos mostrarán también que la extrańa construcción apriorística del empirismo, o especulación que se originaría en las simplicidades propias de la actitud natural, incide sobre algo más que el desarrollo científico.

Iremos muy despacio y como por fragmentos, reconstruyendo primero las conexiones más gruesas y luego las que devienen infinitamente moleculares. El discurso ordoliberal expresa sus correspondientes reparos ante la injerencia del empirismo en la ciencia económica; los expresa las suficientes veces como para despertar la tentación de abordar cada uno de ellos en detalle y de buscar enseguida las visibles confluencias entre los mismos y la crítica de Husserl. Sin embargo, en lugar de ceder a semejante tentación, nosotros preferiremos detectar más bien las dispersiones y los emplazamientos heterogéneos de la aludida crítica. Tal vez las observaciones y los análisis de Walter Eucken ilustren las múltiples y enredadas derivaciones de nuestro problema: "el empirismo no logra conocer la realidad. Basta pensar en la suerte de la Economía alemana durante los últimos decenios, ciencia originada en la justa aspiración de penetrar enérgicamente en la realidad económica y que creó, en verdad, generaciones de economistas a quienes con razón puede 
acusarse de alejamiento de la realidad" (Eucken, 1947: 55). Extraño y paradójico avatar del empirismo: pretender un acercamiento exacto a la realidad económica para terminar alejándose de ella a pesar de todo. Eucken remarca la impotencia irremediable de esta corriente de pensamiento, mientras que Wilhelm Röpke advierte sobre los funestos efectos que acarrearía el apogeo del positivismo y del cientismo en tanto ramas o subgéneros desprendidos del empirismo. La advertencia es también una fuertísima acusación que no debe pasar desapercibida, pues todo indica que a partir de aquí las críticas se encaminan paulatinamente hacia otra suerte de emplazamiento. Según Röpke, el modo de pensar cuantitativo y científico-natural, o la actitud propia del positivismo y del cientismo, comparte la culpa de haber propiciado los más tremendos extravíos de la razón: "se trata de un desvarío de la razón particularmente craso, al que han sido conducidos los hombres del siglo pasado por los éxitos prodigiosos de las ciencias naturales y de la técnica y por la decadencia de la cultura humana" (Röpke, 1949a: 67). ${ }^{3}$ Parecería que Röpke repite y simultáneamente franquea las palabras de Husserl, parecería incluso que las críticas de antaño irrumpen vigorosas en un nuevo punto de combate; mas si así lo fuera, resultaría necesario entonces definir las fuerzas y las estrategias que comienzan a desplegarse desde ese punto. ${ }^{4}$

${ }^{3}$ La responsabilidad restante recae indudablemente en el viejo y siempre reconfigurado pensar dogmático. Cabe mencionar también que las tendencias dogmáticas y las tendencias empiristas formarían parte de la gran antinomia que impide a la Economía constituirse como una verdadera ciencia (Eucken, 1947: 36 y ss.).

${ }^{4}$ Röpke demuestra que los extravíos de la razón no quedan circunscriptos en la actividad científica, sino que además arrastran a las diversas corrientes políticas y económicas. Llegado el caso, nosotros señalaremos que el discurso ordoliberal jamás traslada las críticas de un lado a otro, que sus intenciones no se limitan a establecer una serie de simples y predecibles analogías entre las diferentes esferas del actuar humano; por el contrario, aquel discurso emerge y prolifera alrededor 
Dado que nuestras indagaciones continuarán avanzando de manera lenta y preferentemente entrecortada, conviene atenerse de momento a contestar la siguiente y primordial pregunta: ¿cuáles son las consecuencias perniciosas que acarrearían los extravíos de la razón? O todavía mejor: ¿hasta qué lugares insospechados llegarían tales extravíos? Las críticas de Röpke sostienen que los extravíos afectan gravemente al liberalismo económico de fines del siglo XVIII y principios del siglo XIX: "Se creía seriamente que la economía de mercado regida por la competencia representaba un cosmos en equilibrio, un ordre naturel que sólo necesitaba ser defendido de los ataques exteriores para sostenerse sobre sus propios pies" (Röpke, 1956: 65). El liberalismo muestra síntomas de extravío cuando supone aquello que en modo alguno debería suponerse. En términos concretos esto es que el mercado aparece como un simple producto natural, como un producto que depende única y exclusivamente de las acciones libres y espontáneas. Röpke recuerda que las derivaciones de la concepción naturalista conducen sin más hacia el incuestionable principio del laissez faire: "la misión frente a ese cosmos consiste meramente en quitar obstáculos de su camino: laissez faire; laissez passer" (Röpke, 1956: 65). Asimismo, Eucken agrega que el hábito de equiparar el principio del laissez faire y la competencia de mercado es un error no desarraigado que dificulta enormemente el adecuado desarrollo y la correcta implementación de la política económica (Eucken, 1947: 345). No obstante, resulta claro que el extravío siempre viene después, o que únicamente se desvían y se pierden las cosas en principio encaminadas. No por nada el discurso ordoliberal busca trazar con sumo cuidado el límite exacto de la crítica, el límite que establece la diferencia entre lo acertado y lo extraviado. Así pues, de manera casi simultánea, Röpke y Eucken señalan que el gran acierto del

de cuestiones mucho más profundas, de cuestiones que resonarán luego en las críticas de Husserl. 
liberalismo es el descubrimiento de la competencia como la instancia encargada de regular las acciones y las relaciones de mercado; así también, la crítica ordoliberal no traza límites y divisiones sobre la instancia oportunamente descubierta, sino más bien sobre las actitudes asumidas frente a ella. Como dice Eucken, el problema surge cuando se supone que la competencia está simplemente dada en todos los mercados: "el caso de la competencia perfecta y general no se ha dado ni se da nunca en la realidad; tampoco en la época de los clásicos" (1947: 43). Más tarde o más temprano, muy a pesar suyo, el liberalismo mostraría un halo de ingenuidad; mostraría la actitud propia del hombre que acepta lo dado y que de inmediato depone la posibilidad de formularse cualquier pregunta subsiguiente: "Medito, por lo pronto, como hombre 'ingenuo'. Veo y cojo la cosa misma en persona. Sin duda a veces me engańo, y no sólo respecto de las propiedades percibidas, sino también respecto de la existencia misma" (Husserl, 1985: 89). La crítica ordoliberal quería rodear y demarcar tal actitud: quería demarcarla primeramente para diferenciar las posibles maneras de emitir juicios en torno a la competencia de mercado; quería diferenciarla además para prevenir el extravío que conduce desde la ingenuidad económico-liberal hasta los extremos del escepticismo.

Nuestra indagación continuará su marcha bajo la condición de precisar antes la cuestión que de seguro viene decantándose a través de las últimas líneas: ¿qué indicarían al final de cuentas las críticas precedentes, las críticas que corroen primeramente la concepción del mercado como producto natural y que avanzan luego contra el principio del laissez faire? De seguro, una estrepitosa, aunque no siempre advertida, ruptura entre el liberalismo económico y el ordoliberalismo. ¿ Dónde se trazaría esta ruptura, que separa y aleja a dos corrientes aparentemente unidas, dos corrientes que sólo permanecerían distanciadas por el mero paso del tiempo y por la 
sucesiva sustitución de los nombres? Posiblemente, en ningún otro lugar que no sea ahí donde se enfrentan las actitudes:

los ordoliberales rompen con la tradición del liberalismo de los siglos XVIII y XIX. Y dicen: [...] cuando de la economía de mercado uno deduce el principio del laissez faire, significa en el fondo que todavía está cautivo de lo que podríamos llamar una 'ingenuidad naturalista', es decir, el hecho de considerar que el mercado [...] es de todas formas una suerte de dato de la naturaleza (Foucault, 2008b: 152).

El discurso ordoliberal detallará la serie de desastres económicos y sociales que acarrea la desmedida generalización y la infructuosa puesta en práctica del liberalismo económico, mostrando el mismo ahínco y la misma belicosidad que las demás corrientes críticas surgidas durante el siglo XX. Ahora bien, no por ello se pude suponer el hecho de que la crítica ordoliberal convive pacíficamente con las corrientes e influencias de su tiempo. En todo caso, esa manera de entender las cosas terminaría desatendiendo las especificidades propias del discurso ordoliberal y todavía más: ni siquiera contemplaría la posibilidad de que un discurso cualquiera realice apuestas y despliegue estrategias concretas. El ordoliberalismo postula verdades y a prioris formales que se detectan fácilmente en las críticas precedentes o contemporáneas y que adquieren, a pesar de todo, otra clase de funcionamiento. De ahí que la existencia de una discontinuidad entre el liberalismo y el ordoliberalismo jamás implique una suerte de continuidad entre este último y las corrientes que también chocan contra el primero. Antes bien, la crítica ordoliberal señala algo distinto: la continuidad aparece en el momento de transgredir los límites trazados en el terreno de las actitudes y, como veremos enseguida, el liberalismo económico no es lo único que queda en la parcela de enfrente. 


\section{El escepticismo y la esencia}

Los análisis de Röpke siempre tienen dos caras: hablan de extravíos y de derivaciones perniciosas y, también, de negaciones y de peligros ya cumplidos. Aquí cada tendencia conllevaría necesariamente la presencia de la otra. En otras palabras, el extravío conllevaría una negación, mientras que la negación conllevaría a su vez un extravío. Ambas tendencias se vuelven posibles merced a la persistente ambigüedad que arrastra el concepto de "hecho" y se condicionarían mutuamente desde el instante mismo en que el positivismo y el cientismo pretenden asignar a tal concepto una connotación bien definida: "la de realidad perceptible mediante los sentidos y cuantificable como categoría de la ciencia natural [...], con la rigurosa exclusión de todo otro, en particular del de experiencia 'interna'” (Röpke, 1949a: 68). Extraviarse por negar la experiencia interna y negar la experiencia interna por tornarse extraviado: éste ha de ser el límite a partir del cual ciertas actitudes devienen indistintas; éste ha de ser además el punto donde la ingenuidad roza su extremo opuesto. Husserl sostenía que el avance de las ciencias naturales da lugar a las más crudas reflexiones escépticas; se tratan de reflexiones cuya hostilidad e intransigencia coartan todo tipo de fundamentación científica que no remita hacia la realidad experimentable y efectiva: "Lo que no es realidad, es imaginación, y una ciencia de imaginaciones es, justo, una ciencia imaginaria" (Husserl, 1985: 48). De manera simultánea, Röpke menciona que la intromisión del positivismo en las ciencias sociales genera un peligroso relativismo de valores, de más está decir ahora que dicho relativismo eclosiona y prevalece, precisamente ahí se niega el contenido de verdad de la experiencia interna (Röpke, 1949a: 69). Ingenuidad naturalista, escepticismo y relativismo de valores: la continuidad entre semejantes actitudes revelaría la senda ininterrumpida que conduce desde los extravíos 
del liberalismo hasta el surgimiento de una corriente política y económica mucho más nociva.

Según los términos ordoliberales, la ingenuidad y el escepticismo son actitudes que se engendran mutuamente, que se lanzan y que se empujan entre sí, que avanzan derribando todas las barreras y reparos para alcanzar al final del camino la paradójica convicción de que cualquier cosa resulta posible: "de aquí el cientismo, de aquí el empeño por encontrar en la sociedad regularidades científico-naturales y de aquí la mixtura de hubris cientista y mentalidad ingenieril, con la que se cree poder hacer todo lo que se quiera con el hombre y con la sociedad" (Röpke, 1949a: 68- 69). Extrañas derivaciones escépticas: negar las verdades de la experiencia interna y terminar cayendo en las ingenuas convicciones de una mentalidad ingenieril que ya no encuentra ningún impedimento a la hora de realizar sus más íntimos fines. El discurso ordoliberal precisará entonces la relación de parentesco entre la mencionada actitud y la peligrosísima corriente que se asoma tras la decadencia del liberalismo. Siguiendo el hilo de esa relación, se hablará en principio de intervencionismo y de planificación estatal, se sostendrá a continuación que todo ello conduce hacia el comunismo e incluso hacia el totalitarismo y se postulará finalmente al colectivismo como la culminación misma del extravío económico y político (Erhard, 2011: 18- 20; Röpke, 1949b: 38- 41). Sea del modo que fuere, sólo ahora alcanzan a apreciarse mejor las especificidades y también las estrategias de la crítica; pero sobre todo, sólo ahora se termina de entender lo señalado más arriba: que no existe una suerte de continuidad entre el ordoliberalismo y las demás corrientes alternativas al liberalismo, porque la estrategia ordoliberal traza las discontinuidades en el terreno de las actitudes. El efecto conseguido es más que extraordinario, pues aquellas tendencias a simple vista opuestas, aquellas corrientes históricamente enemistadas, como el liberalismo y el colectivismo, quedarán en adelante 
unidas y bien soldadas. Aunque los despliegues y los movimientos estratégicos no se detienen ahí, sino que siguen avanzando y conquistando otras regiones. Resultaría interesante, a esta altura de hecho imprescindible, observar el modo en que todo ello arrastra y reconfigura al propio pensamiento de Husserl.

Nunca deberíamos olvidar que cada estrategia y cada movimiento ejecutado forman parte de una apuesta específica y concreta, de una apuesta que el discurso arrojará sobre la mesa para modificar y desequilibrar la habitual disposición de las ideas políticas y económicas. Mas por si hace falta, las sucintas palabras de Alfred Müller-Armack nos recordarán qué clase de peculio pone el ordoliberalismo en juego: "A diferencia del antiguo liberalismo, su finalidad no es la restauración del laissez faire; su objetivo es más bien una sintesis novedosa" (Müller-Armack, 2011: 16). La apuesta ordoliberal requiere que el discurso multiplique los movimientos y desdoble las estrategias; requiere igualmente, como suelen demandar casi todas las apuestas fuertes, que la crítica negativa allane y despeje el terreno donde brotará lo supuestamente auténtico y verdadero. Nosotros intentamos mostrar que la primera estrategia del ordoliberalismo allana y divide el terreno de las actitudes, que no busca sencillamente asentarse en el suelo ganado como demarcarlo y seguir adelante. A partir de aquí, correspondería preguntarse entonces cuál sería la actitud posible y además legítima que conjuraría los constantes excesos de una mentalidad extraviada. En otros términos, correspondería precisar la actitud que se asume más allá de la ingenuidad y del escepticismo. No obstante, como siempre, ocurre que el problema planteado dificulta el desarrollo de exposiciones lineales y directas: las dificulta toda vez que los emplazamientos recorridos tienden a dispersarse y yuxtaponerse, sobre todo cuando se advierte que la nueva actitud asumida, la actitud que prolifera entre Husserl y el ordoliberalismo, abarca territorios mucho más amplios e implica cambios mu- 
cho más profundos de lo que podría parecernos inicialmente. Al menos en principio, lo importante es seguir recorriendo los lugares críticos y observar las estrategias allí desplegadas. En efecto, bien puede de este modo, y sólo de este modo, logremos vislumbrar los alcances y las diversificaciones que ya no pertenecen a ningún autor ni a ningún discurso determinado.

La segunda estrategia del ordoliberalismo obedece en gran parte a la necesidad de solucionar el conjunto de cuestiones que la primera dejó pendiente, más aún: ahora todas las críticas parecerían girar alrededor de un asunto apremiante y ciertamente impostergable. Sin lugar a duda, se trata de definir la competencia de mercado y se trata de pensar y de elaborar postulados evitando las derivaciones que conducen hacia el principio del laissez faire. El camino contiene serios obstáculos y desafíos, ante todo, porque la crítica cerró la posibilidad de recurrir a cualquier intento del pasado y, más fundamentalmente, porque la señalada y cuestionada exacerbación de los errores ya cometidos inhibe las esperanzas puestas en el presente. Imposibilidad de remitirse al pasado e inutilidad de comenzar desde el presente: he aquí los variados y continuos efectos que generan los límites trazados mediante la crítica. Por supuesto, de aquí también se sigue el desafío y la apuesta del ordoliberalismo: prescindir de cualquier saber previo para comenzar prácticamente desde cero y comenzar de cero para que los saberes previos se ordenen en función de la nueva actitud asumida. Eucken lo dice sin tapujos: "No interesa la mera continuación de una línea de pensamiento [...]. Prescindimos en absoluto, por el momento, del contenido científico de toda la Economía recibida. En este punto, nuestra actitud debe ser radical" (Eucken, 1947: 98). Semejantes afirmaciones indican evidentemente una importante parte del desafío y de la consiguiente apuesta que el discurso ordoliberal realiza frente al mismo (aunque no más que una im- 
portante parte, pues cabe recordar que aquí las cosas siempre se desdoblan).

Al fin y al cabo, la actitud asumida resulta tan original y tan radical que no sólo prescinde de todo saber previo, sino también de la incoherente colección de ejemplos que brindaría la estricta realidad presente. El ordoliberalismo sostiene constantemente que la realidad económica y política de principios del siglo XX no muestra indicio alguno sobre la existencia de la competencia o sobre la eventual injerencia de sus funciones reguladoras. ¿Y cómo llegaría a mostrar algún indicio si la desventurada aplicación del laissez faire produce las imperfecciones y los desequilibrios que estrangulan pronto a la competencia de mercado? Pero además, ¿qué caso tendría seguir insistiendo después de que las sucesivas crisis económicas avivaron el intervencionismo de tipo colectivista? Ante esta situación, los análisis de Röpke advierten que la economía de mercado adopta ciertas formas de desenvolvimiento, ciertas formas que, como tales, llegan a darse efectivamente o no. En términos más sencillos, a modo de ejemplo, se podría observar perfectamente que la economía de mercado adquiere una forma bien determinada de desenvolvimiento y se podría constatar también que la misma conlleva oscilaciones y desequilibrios permanentes. Mas no por eso se debería concluir en el hecho de que economía de mercado pierde entonces la posibilidad de desenvolverse de una manera distinta: "la economía de mercado y la competencia altamente diferenciada se ordenaron en estas formas históricas; pero lo mismo hubieran podido organizarse de otro modo" (Röpke, 1956: 142). De ahí la necesidad de establecer la correcta distinción entre lo esencial y lo mudable o entre la forma pura y las formas históricas de la economía de mercado: "se tiende demasiado a confundir lo secundario y variable con lo que es básico; lo accesorio con lo esencial' (Röpke, 1956: 142). De ahí también el desafío restante y la apuesta plena del discurso ordoliberal: buscar una alternativa 
supuestamente auténtica y verdadera, una alternativa que supere las falsas recetas ofrecidas por el liberalismo o el colectivismo.

No habrá duda de que ello exige esfuerzo e imaginación y, a entender de Röpke, lo exigirá aún más cuando la incapacidad de proyectar otra cosa que lo ya dado conduzca hacia la convicción de que no existen más alternativas que las presentes: "el liberalismo lleva derechamente a la conclusión de que el sistema económico y social del mundo de Occidente está irremisiblemente perdido" (Röpke, 1956: 143-144). Sobre todo en tiempos de crisis y de fluctuaciones económicas, ello exigirá también un enorme empeño de la inteligencia. Como sostiene Eucken, los tiempos de crisis siempre empujan a plantear nuevas preguntas: "La mera descripción de hechos no conduce lejos. Lo que importa es la pregunta, y en especial la formulación de preguntas esenciales" (Eucken, 1947: 305). Capacidad de imaginación, esfuerzo de la inteligencia y formulación de preguntas esenciales: cada reivindicación señala la actitud que convendrá asumir en adelante y arrastra además a la propia filosofía de Husserl. Seguramente esa filosofía pretenda comenzar desde cero y seguramente necesite prescindir también de todo saber previo y de toda realidad fáctica. Ahora bien, el trecho ya recorrido debió dejar bastante claro que aquí no nos interesa tanto la detección y la confirmación de las grandes coincidencias como la apreciación de una posibilidad más discreta, a saber: que las ideas se arrastren en diferentes direcciones y que las diferentes direcciones constituyan emplazamientos extraños y ajenos a dichas ideas. La filosofía de Husserl resuena en la alternativa del ordoliberalismo, mientras que la alternativa del ordoliberalismo resuena a su vez en la filosofía de Husserl; quizá entre esta filosofía y aquella alternativa emerja la actitud que de algún modo resuena en nosotros mismos. Como siempre, estas indagaciones seguirán marchando lento y componiendo fragmentos. 
La filosofía de Husserl señala que la realidad fáctica e individual, la realidad que la actitud natural toma como simplemente dada, resulta variable y contingente: "Es así, pero pudiera por esencia ser de otra manera" (Husserl, 1985: 19). Que las cosas dadas puedan ser de otra manera implica entonces que el sentido de lo contingente posee una esencia, un eîdos, cuyas verdades esenciales llegan a aprehenderse en toda su pureza. La extensa y precedente serie de críticas permite admitir provisionalmente que el eîdos carece de existencia fáctica $\mathrm{o}$, mejor dicho, que la realidad de este nuevo objeto difiere de la realidad simplemente dada a la actitud natural. De modo tal que sólo faltarían precisar dos cuestiones entrelazadas: de qué realidad se trata y cómo la misma llega a aprehenderse en toda su pureza. Pero aquí querríamos desviarnos un poco del camino indicado, no por la mera necesidad de resumir nuestro recorrido o de esquivar los innumerables detalles, sino más bien por la persistente sospecha de que el pensamiento de Husserl también resuena en otra parte. Más arriba se observaba que la alternativa ordoliberal requería principalmente de esfuerzo y de imaginación; ahora cabría remitirse a Husserl y agregar que la aprehensión de esencias solicita el ejercicio de una capacidad muy especial, de una capacidad que despliega y multiplica las realidades dadas: "Ante la mirada abarcadora que sobrevuela la infinitud abierta de variantes, lo idéntico que se mantiene fijo en la variación se alza con evidencia como identidad que atraviesa las variantes, como la esencia común a ellas, como su idea" (Husserl, 2012: 15). Interesante modo de encontrar lo idéntico y esencial, de hacer que emerjan las posibilidades puras tras la simple realidad fáctica y actual. Hay que percatarse no obstante de esa salvedad que Husserl recuerda continuamente y sin la cual las palabras y las ideas recién esbozadas perderían intensidad y también resonancia; después de todo, ¿la capacidad de variación comienza única y necesariamente por la realidad concreta y estricta?, ¿sólo a partir de ahí se llega ha- 
cia la correcta aprehensión de las esencias? Sucede que la capacidad o el empeño en cuestión prescinden siempre de ciertas diferencias: "Para la consideración de esencias están en pie de igualdad la percepción y la representación de la fantasía; se puede destacar visiblemente, se puede abstraer la misma esencia igual de bien a partir de ambas, y las posiciones de existencia que van enlazadas a ellas son irrelevantes" (Husserl, 1982: 81). El discurso ordoliberal sostenía que la economía de competencia no debería concebirse como un dato natural que depende meramente de las conductas libres y espontáneas; además, observaba que los extravíos del liberalismo y los posteriores excesos del colectivismo borraron todo indicio y todo rastro que permita certificar la existencia o la eventual injerencia de aquella clase de economía. Ahora nosotros advertimos que a pesar de tales impedimentos, que a pesar de tener delante de sí una realidad sumamente opresiva y apremiante, no resulta imposible imaginar o proyectar a la economía de mercado y desde allí aprehender la verdadera esencia de la misma. Ahora nos preguntamos también qué cosas concierne imaginar y qué suerte de esencias y verdades allí se han de encontrar.

Determinados fragmentos y pasajes hallados en la vastísima obra de Husserl otorgan la pauta y la incipiente respuesta: "fingimos actos de experimentar algo, de querer algo, etc., en ellos podemos por 'ideación', intuir originariamente, y en casos incluso adecuadamente, múltiples esencias puras" (Husserl, 1985: 23). No sólo es posible imaginar figuras geométricas, colores o melodías y luego encontrar la esencia que pertenece a cada una, también se vuelve perfectamente lícito imaginar las diferentes voliciones y los variados estados intrafectivos para aprehender entonces sus correspondientes esencias. Bien, el ordoliberalismo busca las formas o los principios esenciales que constituyen a la economía de mercado (los que necesitan distinguirse de todo desenvolvimiento histórico y concreto) realizando proyecciones sobre las voliciones y 
los modos de comportamiento. La búsqueda hablará de hechos y de datos, sin embargo no remitirá hacia las incoherencias de la realidad empírica. El esfuerzo imaginativo derivará en la postulación de principios y de verdades innegables, pero sin recurrir a alguna condición concebida a priori. Se pretende comenzar efectivamente desde cero, y comenzar de cero significará en definitiva adoptar una actitud específica dentro del terreno propio de las actitudes.

Eucken señala que los individuos elaboran e implementan planes económicos: "En todos los tiempos y en todos los lugares, la actividad económica tiene lugar en virtud de planes económicos y a través de su ejecución. En resumen: todo el obrar económico se basa en planes" (Eucken, 1947: 115). La actividad económica parte de una cantidad de hechos más o menos grande que los individuos consideran como datos; así, por ejemplo, un plan económico considera las necesidades del individuo y los medios destinados a satisfacerlas, o bien considera ambos datos más los planes y acciones que implementan otros individuos. Los diferentes datos considerados reflejan la diversidad de planes elaborados e implementados. En efecto, el plan que parte únicamente de medios y necesidades difiere enormemente del plan que incluye la consideración de otros planes y acciones. La diversidad de planes elaborados indican finalmente las formas esenciales y constitutivas que orientan el desarrollo de toda economía concreta. Así pues, si el primer plan se elabora e implementa obedeciendo a la forma de una economía autárquica, el segundo se lleva delante de acuerdo a la forma de la economía de mercado o de tráfico: "los numerosos jefes de explotaciones o de economías de consumo que conviven en una comunidad del tipo de economía de tráfico, deben tener en cuenta en su propio plan las acciones y los planes de los demás. Todas las economías individuales se encuentran en una relación de dependencia mutua" (Eucken, 1947: 105). Vemos entonces que la búsqueda comienza en el terreno de los planes y de los datos y que 
desde allí llega hasta las esencias y principios. Vemos también que los esfuerzos y las proyecciones no conciben al mercado como un fenómeno natural y espontáneo sino, más bien, como la forma ordenadora de las posibles y diversas actividades económicas: "Economía de tráfico' es una forma básica pura, constitutiva y de tipo ideal" (Eucken, 1947: 126-127). Al menos inicialmente, diríase que la economía de tráfico es la esencia de cierto comportamiento humano, que quizá no esté dado en la realidad actual y que, a pesar de todo, puede imaginarse y proyectarse. Pero la cuestión no se detiene aquí, puesto que las actividades ordenadas bajo los principios de la economía de tráfico o de mercado muestran también otras formas específicas de configuración. Los análisis de Eucken indican que esa economía adopta formas tales como el monopolio, el oligopolio y, por supuesto, la competencia. En otros términos, indican que el mercado posee una morfología que orienta de distintas formas, o según distintos principios, la efectuación de los planes individuales. Nosotros deberíamos detenernos en la definición ordoliberal sobre la competencia de mercado, pues nos parece que a partir de ella todo el asunto se desplaza hasta los lugares más recónditos e insospechados.

El consabido asunto queda inicialmente establecido en pocas palabras y medidas palabras: "Lo único decisivo es el hecho de que el individuo, a causa de las dimensiones del mercado y de lo exiguo de su oferta o demanda, [...] considera el precio como un dato en su plan y actúa en consecuencia" (Eucken, 1947: 138). Esta escueta y apretada definición expresa un importante aspecto sobre la competencia: que la posición y la influencia de toda actividad económica resulta siempre reducida o, más sencillamente, que los diferentes planes se encuentran ordenados y relacionados de acuerdo a una forma cuya rigidez misma impide la introducción de cualquier tipo de modificación en los precios. Ahora bien, más allá de marcar las divisiones internas de la morfología perteneciente 
al mercado y más allá de advertir también que la competencia se separa tajantemente del monopolio y del oligopolio, la definición citada suscita de inmediato las más extraordinarias derivaciones. Röpke mencionará que la virtud fundamental de la competencia de mercado consiste en imposibilitar la obtención de beneficios espurios o la prolongación de deficiencias impunes: "todo está dispuesto en forma que las deficiencias se castiguen inexorablemente con pérdidas y finalmente con la quiebra”. Se trataría de una perfecta conjugación entre el éxito económico, la responsabilidad empresarial y el riesgo de participar en el juego:

El principio de conjugación, según el cual los que dirigen el proceso de producción son quienes disfrutan los beneficios o soportan personal e íntegramente el daño del fracaso, y, a la inversa, los que aceptan las posibilidades de ganar o perder son quienes dirigen la producción, es uno de los más importantes principios [...] de nuestra constitución económica (Röpke, 1956: 132).

Se trata también de aquella forma que en sí misma, o dentro de sí misma, entrecruza las fuerzas reguladoras del proceso económico y los resortes estimuladores del trabajo y de la producción. El discurso ordoliberal sostiene constantemente que la competencia posee una lógica interna sumamente virtuosa. En efecto, su extrema rigidez garantiza la traducción de todo error en pérdidas y de toda sucesión de pérdidas en la quiebra o la exclusión del juego, mientras que su exacto mecanismo de traducción entre acciones y posiciones de mercado despierta en todo individuo la necesidad de meditar, de vigilar y eventualmente de modificar los planes llevados adelante. De ahí que la competencia no dependa de las conductas libres y espontáneas, de ahí que tampoco se presente como un simple dato natural: "En realidad, la competencia sólo debe sus efectos a la esencia que posee, que la caracteriza y la constituye. No debe sus efectos benéficos a una anterioridad natural, 
un dato natural que resida en su seno. Los debe a un privilegio formal. La competencia es una esencia. La competencia es un eîdos" (Foucault, 2008b: 153). Hemos visto aquí que las concepciones ordoliberales solicitan el esfuerzo de la inteligencia y el despliegue de la capacidad imaginativa, mas todavía nos faltaría advertir que la irradiación de una solicitud semejante no se extiende sucesivamente entre las supuestas esferas del actuar humano — sean la filosofía, la ciencia económica y la política - sino que más bien se dispersa y resuena entre los modos de comportamiento asumidos por los individuos comunes y corrientes. Así pues, si siguiésemos recorriendo esa intrincada dispersión, nuestra indagación llegaría a vislumbrar también, aunque a vislumbrar únicamente, la amplitud de la apuesta realizada y la radicalidad de la alternativa buscada.

\section{El gobierno y el ejercicio de una actitud}

Ya es hora de que las cosas adquieran velocidad y de que los fragmentos vayan migrando hacia el nuevo emplazamiento. Ya es hora de que los nombres y las influencias se disuelvan completamente y de que olvidemos, después de tantas idas y venidas, la tentación de confirmar aquella relación que debía desecharse a toda costa. Hubiese resultado mucho más sencillo suponer que el discurso ordoliberal traslada las críticas de Husserl de una esfera a otra o que las palabras pronunciadas en la esfera del saber filosófico se pueden repetir de manera más o menos exacta en las esferas de la economía y la política. Pero las palabras no se repiten ni se suceden entre sí y las críticas jamás quedan circunscriptas en tal o cual esfera del actuar humano; antes bien, las palabras se dispersan y las críticas resuenan hasta el punto mismo de emerger por fuera de toda esfera establecida. Las críticas emergen por fuera, ¿y luego qué?, ¿en dónde despliegan las estrategias y desatan las batallas? Tal y como se desprende del discurso ordoliberal, la proyección 
de posibilidades y la aprehensión esencias equivale a pensar las relaciones internas que dirigen y ordenan la marcha de la realidad; equivale, en términos más simples, a que la inteligencia observe los diferentes órdenes y elabore preguntas sobre sus correspondientes interconexiones: "El orden económico no debe considerarse sólo en sí, sino como la parte de la vida total de un pueblo [...]. Porque esto es el orden económico [...]. Si pensamos en nuestra economía actual, la vemos, sin más, como una parte de la existencia total del pueblo en conexión con su ser natural, espiritual y político" (Eucken, 1947: 89). En lugar de saltar de una esfera a otra y de traficar recetas entre una esfera y otra, el discurso ordoliberal busca la solución de un insoslayable problema vital. En lugar de pronunciar las críticas que a nadie se le ocurría pronunciar dentro del saber y de la práctica económica o política, las alternativas propuestas procuran actuar directamente en el terreno de las acciones y conductas. Esto es lo que destella a través de cada crítica y de cada indicación previa. Al fin y al cabo, que la competencia de mercado aparezca como la esencia o la forma ordenadora de cierto comportamiento humano, que su propia lógica conjugue las fuerzas reguladoras y los resortes estimuladores, implicaba aquí que la competencia de mercado exige la adopción de un modo de comportamiento bien determinado. El gran error del liberalismo económico consiste entonces en no extender sus proyecciones más allá de las conductas egoístas. Dicho de otra manera, el gran error fue creer que las conductas egoístas y la competencia de mercado conviven en perfecta armonía natural: “¿Basta [...] apelar a una especie de 'esclarecido egoísmo' de los hombres a fin de que reconozcan que para ellos mismos es lo más provechoso supeditarse a la disciplina del mercado y de la competencia?" (Röpke, 1960: 168). Se cree que el egoísmo ha sido desde siempre la motivación fundamental de cualquier conducta económica y puede que eso resulte acertado, sea como fuere, el discurso ordoliberal advertirá que el egoísmo no 
basta, pues la persecución desenfrenada del propio interés genera el estrangulamiento de la economía de mercado. La estrechez de miras o la falta de claridad, la incapacidad de no considerar otra cosa más que un puñado de intereses inmediatos, impiden que los hombres aprehendan las verdades esenciales de aquella economía, las verdades que serían tan innegables como provechosas para ellos mismos.

$\mathrm{Al}$ parecer, el liberalismo económico desconoció este problema vital, porque él tampoco tuvo la suficiente capacidad e inteligencia, porque no entendió o porque pretendió cerrar los ojos ante el hecho de que la competencia de mercado remite necesariamente hacia una serie de relaciones e interconexiones extraeconómicas: "se aceptó como producto natural lo que, en realidad, es un producto artificial muy frágil de la civilización” (Röpke, 1956: 66). De manera tal que la incapacidad de proyección, la pereza del pensamiento y todos los extravíos posteriores no permitieron reconocer que la competencia de mercado es un producto artificial y sumamente frágil, un producto cuya existencia misma requiere de condiciones y de disposiciones vitales que nunca se dan de modo natural. Al vislumbrar el supuesto modo en que semejantes condiciones llegarían a darse vislumbramos, simultáneamente, la amplitud de la apuesta ordoliberal y, al vislumbrar la amplitud de la apuesta, nos percatamos pronto de aquellas derivaciones y dispersiones que resuenan en nosotros mismos. Si las cosas no se dan naturalmente, o si no aparecen allí donde el pensamiento somnoliento pretendía encontrarlas, habrá que cambiar de actitud y llevar adelante las tareas correspondientes: "la gran tarea de la era actual consiste en dar a esta economía nueva e industrializada un orden duradero, capaz de funcionar y digno del hombre. Esta tarea, de cuya solución satisfactoria depende algo que es decisivo (y no sólo para la existencia económica de los hombres), exige la creación de una 'constitución económica' utilizable" (Eucken, 1947: 324). La 
práctica gubernamental debe adquirir la capacidad de proyección y de aprehensión para ordenar luego todas sus intervenciones de acuerdo a los comportamientos proyectados y a las verdades aprehendidas. Ludwig Erhard señalaba la exigencia mediante unas sencillas palabras: "en el mundo libre, un pragmatismo superficial o un conformismo pernicioso impregnan cada vez más la conciencia política. Y quien naturalmente no advierte ni aprecia el valor del orden como marco de vida, tampoco es capaz de defenderlo y apoyarlo" (Erhard, 2011: 13). Nótese entonces que la elaboración de una concepción específica sobre la competencia conlleva el trazado de una novedosa modalidad de acción gubernamental. Así pues, la apuesta consiste ahora en dirigirse hacia el tejido social, en desplegarse a través del espeso entramado de conexiones y de contactos que generan las diferentes actividades humanas, para conformarlo gradualmente según los principios que definen a la competencia de mercado. Así también, en el límite de todo ello, la acción gubernamental tiene que hacerse cargo de las conductas reales y guiarlas hasta el terreno de las conductas imaginadas y proyectadas.

Entre la competencia como forma ordenadora y el desenvolvimiento efectivo de sus rígidas funciones, entre la esencia y la realidad actual, se traza una esforzada y permanente acción gubernamental: "La competencia pura no es un dato primitivo. No puede sino ser el resultado de un prolongado esfuerzo, y, en rigor, nunca podrá alcanzarse. La competencia pura debe y no puede ser más que un objetivo, un objetivo que supone, por consiguiente, una política indefinidamente activa" (Foucault, 2008b: 153). A esa política le corresponderá definir y redefinir el espacio en el cual funcionen los principios esenciales de la competencia de mercado o, todavía mejor, le corresponderá modificar las cosas dadas para que los hombres sientan en sí mismos y por sí mismos las nuevas exigencias y solicitudes. Tal vez la crítica haya permitido que el saber científico aprehenda las esencias y las formas y, tal vez, el 
saber científico haya aportado los fundamentos de una técnica política racional (Eucken, 1947: 221 y 325; Husserl, 2012: 4). Sin embargo, los esfuerzos quedarían inconclusos si la actitud asumida dejase de propagarse y de generalizarse. Resultará necesario que la técnica política se constituya como una política vital que permita a los hombres ver aquello que aún no ven. Resultará necesario que los hombres aprehendan las esencias o las formas y que asuman lo aprehendido como una convicción inquebrantable: "debía ser posible ganar la confianza de amplios sectores de la población hacia los logros de la economía de mercado. Cualquier ordenamiento de la sociedad necesita sólo una simple señal para hacer visible su voluntad. [...] Hoy ya se evidencia una valoración positiva del principio de competencia que va abarcando círculos cada vez mayores" (Müller-Armack, 2011: 19). Extraña derivación del propio discurso ordoliberal: aprehender las esencias o las formas ordenadoras y elaborar enseguida los parámetros de una política gubernamental cuyo objetivo no será otro que hacernos cambiar de actitud.

\section{Bibliografía}

Bilger, François, 1964, La pensée économique libérale dans l'Allemagne contemporaine, París, Librairie Générale de droit et de jurisprudence.

Castro-Gómez, Santiago, 2010, Historia de la gubernamentalidad. Razón de Estado, liberalismo y neoliberalismo en Michel Foucault, Bogotá, Siglo del Hombre.

Eucken, Walter, 1947, Cuestiones fundamentales de la economía politica, I. Lacoste (trad.), Madrid, Revista de Occidente.

Erhard, Ludwig, 2011, "Una política económica orientada hacia la 'integración interna de la sociedad", Cuadernos empresa y humanismo, núm. 38, Universidad de Navarra, pp. 6-21. 
Foucault, Michel, 2008a, La arqueología del saber, A. Garzón del Camino (trad.), Buenos Aires, Siglo XXI.

\section{Buenos Aires, FCE.}

Husserl, Edmund, 1982, La idea de la fenomenología, Madrid, FCE.

- 1985, Ideas relativas a una fenomenologia pura y a una filosofía fenomenológica, J. Gaos (trad.), Madrid, FCE.

- 2012, Renovación del hombre y de la cultura, A. Serrano de Haro (trad.), Madrid, Anthropos.

Müller-Armack, Alfred, 2011, "Economía social de mercado", en Una mirada a la teoría, a los modelos económicos y a la economía social del mercado. Reflexiones teóricas para Bolivia, La Paz, Konrad Adenauer Stiftung, pp. 15-19.

Röpke, Wilhelm, 1949a, Civitas Humana, T. Muñoz (trad.), Madrid, Revista de Occidente.

1949b, La crisis del colectivismo, D. Seeling (trad.), Buenos Aires, Emecé.

— 1956, La crisis social de nuestro tiempo, T. Muñoz (trad.), Madrid, Revista de Occidente.

— 1960, Más allá de la oferta y la demanda, R. Ortalá (trad.), Valencia, Fomento de Cultura.

(Artículo recibido el 7 de enero de 2014; aceptado el 25 de febrero de 2014) 